\title{
Material Parameters Identification for Modelling of Carbon Rod Structures Delamination
}

\author{
Kęstutis ŠPAKAUSKAS*, Paulius GRIŠKEVIČIUS**, Kazimieras PETKEVIČIUS***, \\ Vitalis LEIŠIS***** \\ *Kaunas University of Technology, Studentu 56-331, 51424 Kaunas, Lithuania, E-mail: kestutis.spakauskas@ktu.lt \\ **Kaunas University of Technology, Studentu 56-340, 51424 Kaunas, Lithuania, E-mail: paulius.griskevicius@ktu.lt \\ ***Kaunas University of Technology, Studentu 56-340, 51424 Kaunas, Lithuania, E-mail: kazimieras.petkevicius@ktu.lt \\ ****Kaunas University of Technology, Studentu 56-343, 51424 Kaunas, Lithuania, E-mail: vitalis.leisis@ktu.lt \\ crossref http://dx.doi.org/10.5755/j02.mech.19652
}

\section{Introduction}

Over the past 25 years, the use of advanced composite materials in aircraft primary structures has increased significantly. The main requirements are fuel-efficient, lightweight, and high-stiffness structures that have fatigue durability and corrosion resistance. However, there are major differences between metal and composite damage mechanics and durability concerns. Despite the many advantages, composite structural certification becomes challenging due to the lack of experience in large-scale structures, complex failure mechanisms, sensitivity to temperature and moisture, and scatter in the data, especially in fatigue [ $1-3]$. Compared to the metal static and fatigue data, composite materials have high data scatter due to their anisotropic heterogeneous characteristics, such as lay-up, manufacturing defects and imperfections, test complications, and environment.

One of the reasonable places of crack formation between two plies could be the abrupt changes of section, such as ply drop-offs, unions between stiffeners and thin plates [4]. Stress concentration formation in this area can be cause for damage and delamination in a composite layup. Such zones are common for structural parts of gliders. After full-scale lab fatigue testing of glider wing spar, the white spots noticed in the tapered wing spar end areas is example of delamination initiated of ply drop-offs zones where bonded carbon fiber rods represent the tapered end of glider's wing spar.

Fatigue delamination growth is very important for the composite structures used in vehicles and aircrafts. But, before studying the interlaminar cracks growth under fatigue loading, it is necessary to correctly describe the phenomena of delamination mechanics under static loading.

The Finite element (FE) method is very effective tool to analyse the phenomena of delamination mechanisms. There are several ways to model delamination: cohesive zone elements, tiebreak contacts, virtual crack closure technique. For most of those methods it is needed special material properties and simulation parameters as energy release rate, contact and fracture parameters, shear, and normal stresses as well as element size. Highly harmful interlaminar shear (ILS) stresses develop at local discontinuities such ply-drops, bonded and bolted joints, or during handling, assembly, or foreign object impact [1]. These stresses need to be evaluated for structural applications, and delamination growth is the fundamental issue in the evaluation of lami- nated composite systems for durability and damage tolerance.

Delamination can be affected by such material properties as interlaminar shear strength and fracture toughness. Exist many of testing procedures for the characterisation of composite delamination failure criteria, while some of them are very sensitive to the quality of performed test.

The aim of the present work is to compare the interlaminar shear strength and fracture toughness of glued carbon fiber rods obtained using different experimental approaches and apply the parameters identification approach to characterise the interlaminar properties for reliable simulation of the delamination by using LS-OPT. To develop the finite element model capable of simulating the damage process of bonded connection and to calibrate the interlaminar connection and delamination criteria by using the parameter identification methodology.

\section{Experimentation methods}

The investigation object was Graphite SM315 carbon fiber rods, used in sailplane wing spar construction. Sailplane wing spar is formed by bonding CF rods together in corresponding shape. CF rods are produced by the pultrusion method and have a square profile of $3 \mathrm{~mm}$ by $3 \mathrm{~mm}$. Such material is more than six time stronger than aluminum, twice as stiff and only half its weight [5].

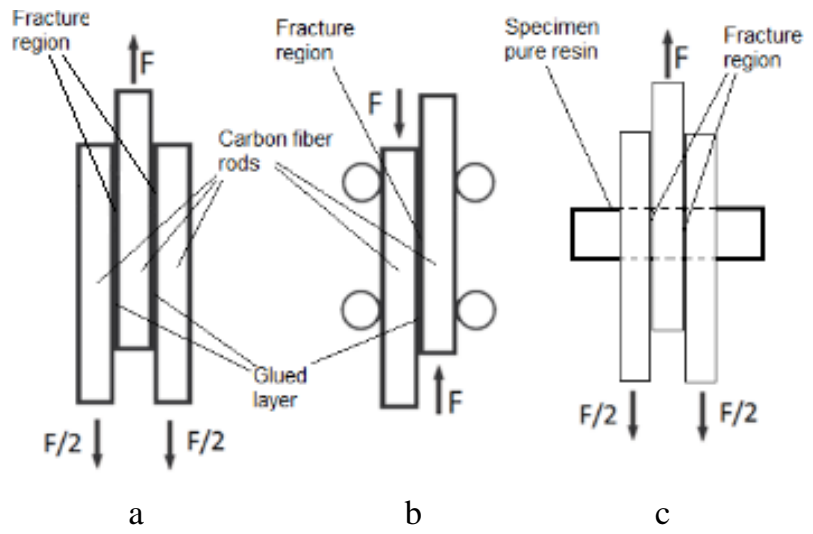

Fig. 1 Types of interlaminar shear tests a) tension; b) single shear; c) double shear

Experiments of this work were divided into two parts: various tests (tension (Fig. 1, a), single shear (Fig. 1, b) and double shear (Fig. 1, c) tests) to define interlaminar shear strength and delamination experiments according to 
ASTM D5528 [14] and ASTM D7905 [15] test standards to obtain interlaminar fracture toughness (mode I (Fig. 2, a)

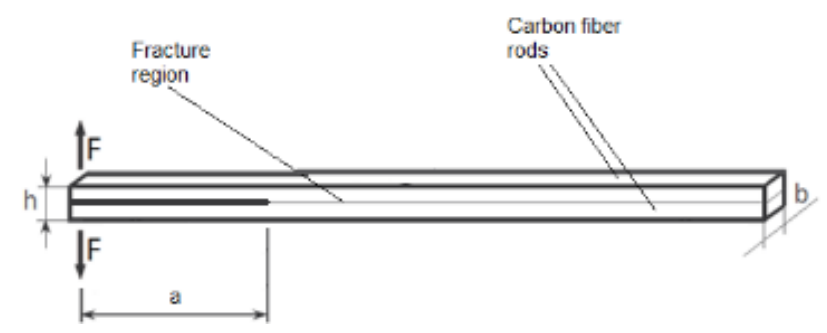

a and mode II (Fig. 2, b).

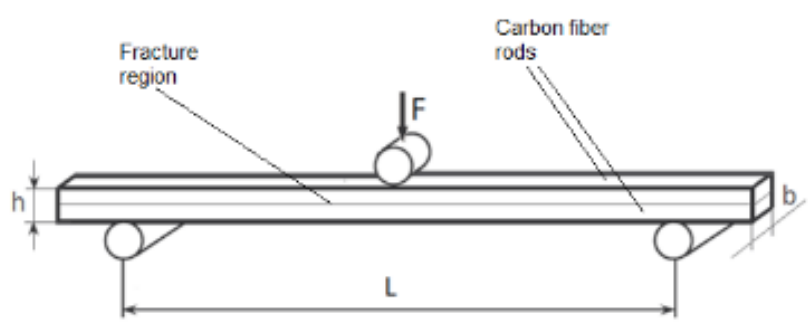

b

Fig. 2 Types of delamination tests a) mode I; b) mode II

For the following experiments, various groups of specimens were bonded in different configurations and dimensions by using CR83 epoxy resin and CH83-2 hardener. $\mathrm{CF}$ rods were stacked one on top another with epoxy layer in between. Composite specimens were made by hand layup process in special mold to prevent shifting. All specimens were pressed with equal $5 \mathrm{~N}$ force to ensure even distribution and thickness of matrix layer between carbon fiber rods. The samples were prepared at room temperature and postcuring has been done in according to manufacturer datasheet; 8 hours at $55^{\circ} \mathrm{C}$.

$130 \mathrm{~mm}$ specimens with $50 \mathrm{~mm}$ initial pre-crack were fabricated for mode I delamination testing. Tests took place as shown in Fig. 2, a. Instron ElectroPlus E10000 testing machines synchronized with a Phantom v711 highspeed camera were used for this experimental setup. Precise synchronization between testing machine and high-speed camera allowed recording crack growth at 100 fps rate during full breakage of the sample. Delamination growth (length) was determined from image data and related load values were taken from testing machine.

To evaluate the interlaminar shear strength and the fracture toughness of mode II, different tests, dimensions, and loadings had been selected: three-point bending (mode II) (Fig. 2, b), interlaminar shear by tension (Fig. 1, a), compression (single shear) (Fig. 1, b) and pure shear of epoxy resin (Fig. 1, c). Tinius Olsen H25k universal testing machine was used for above-described tests. Fabrication of specimens (dimensions and configuration) was described in more details in conference paper [6].

\section{Experimental results}

\subsection{Interlaminar shear strength}

Interlaminar shear strength has been evaluated by 5 different test types. During the three-point bending test, depending on the specimen length, three types of damage were observed. In shortest specimens the first peaks caused by delamination. After the load drops, it is starting to rise again, then the fracture in the compressed layer observed. In the longest specimen (L100) failure without delamination and fracture occurs in the compressed layer.

In the L25 experiment, the load drops slightly and starts to increase, but never reaches the previous maximum value. Finally, the lower surfaces were damaged.

In the L50 experiment, after the second peak, the load drops slightly then increases, drops a little bit again and starts to rise again. Then the maximum load value is reached, and the lower surfaces are damaged. The load starts to drop off and the experiment finishes.

L100 experiment is different from previous two. Specimens do not experienced delamination. The load raised till the upper surface (compressed layer) started to crack. For this reason, interlaminar shear stresses were calculated using following equation (valid up to delamination):

$$
\tau=\frac{3 F}{4 b \cdot h},
$$

here: $b, h$ are width and height of the specimen.

The maximum normal stresses at the outer surface of the specimen were calculated using two equations. Before delamination:

$$
\sigma=\frac{3 F \cdot L}{2 b \cdot h^{2}} .
$$

After delamination:

$$
\sigma=\frac{3 F \cdot L}{b \cdot h^{2}},
$$

here: $L$ is support spacing distance.

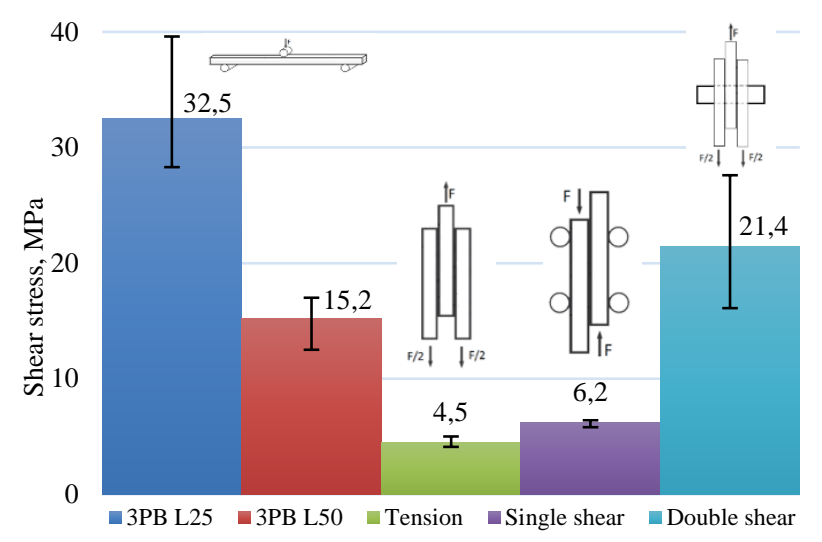

Fig. 3 Comparison of interlaminar shear test results

$L 25$ and $L 50$ tests showed that greater distance between supports lower interlaminar shear stress the specimen can handle. While the distance between supports increased twice (from $25 \mathrm{~mm}$ to $50 \mathrm{~mm}$ ), the average interlaminar shear strength decreased a bit more than twice (from 32,5 $\mathrm{MPa}$ to $15,2 \mathrm{MPa}$ ). 
Tensile test of double and single glued rods gave the smallest values (4.5 and 6.2 MPa) of interlaminar shear strength respectively. Both methods must be used carefully because of the results are sensitive to the alignment accuracy during the manufacturing and fixture. Single shear test with average value of $6.2 \mathrm{MPa}$ also is quite far from the values obtained by other test methods. Here also the bending take place, which decreases the shear strength values. This gave quite different results compared to three point bending test.

Double shear test with cylindrical pure resin samples gives the average shear strength values of $21.4 \mathrm{MPa}$.

Comparison of all test results (min, max and mean values) of interlaminar shear stress presented in the figure 3 . More detailly the test results are presented in conference paper [6].

\subsection{Fracture toughness Mode I}

For an accurate simulation and prediction of the interlaminar cracking process and delamination the interlaminar fracture toughness must be determined.

During the interlaminar fracture toughness experiments the CF rods being as high bending stiffness elements caused the unstable crack growth. From the force versus displacement diagram the interlaminar fracture toughness were calculated according to international ASTM D5528 standard while the Blake et al. [7] state that standard methodology is not suitable for unstable crack growth scenario. To follow experimentation procedure according to previously mentioned standard becomes complicated due to actual increment of delamination growth being more than specified ( 3 to $5 \mathrm{~mm}$ ). To calculate interlaminar fracture precisely it is necessary to record crack growth at each propagation point. Therefore, for the measure of unstable crack growth the high-speed camera was used.
A typical load-displacement diagram obtained under the mode I test of DCB (Double Cantilever Beam) specimen is presented in Fig. 4. In the beginning load increased gradually although crack did not propagate. At the certain point sudden and partial crack opening occurred (Fig. 4 segment 1) resulting the load drop. Experiment continued in the same manner till the full breakage. Load curve was sawtooth type with few peaks. Crack propagation was unpredictable. Each other specimen acted in the similar way. Such phenomena are called as unstable crack growth. In the Fig. 4 on the crack growth curve is it showed 6 increments of delamination growth and in the Fig. 5 these increments are marked on the specimen.

After the completion of delamination (mode I) experiments, interlaminar fracture toughness was calculated according following equation [8]:

$$
G_{I C}=\frac{3 F \cdot \delta_{I}}{2 b \cdot a}
$$

here: $F$ is load; $\delta_{I}$ is displacement of point where the load is applied; $b$ is width of the specimen; $a$ is delamination length (Fig. 2, a).

Unstable crack growth resulted high data scatter and interlaminar fracture toughness varies from $71 \mathrm{~J} / \mathrm{m}^{2}$ to $317 \mathrm{~J} / \mathrm{m}^{2}$ from the 12 experiments with an average value of $153 \mathrm{~J} / \mathrm{m}^{2}$. Current experiment setup allowed to record load value and crack length at every increment of delamination. $G_{I C}$ was calculated at corresponding points. The fracture toughness and respective load value throughout the whole experiment are presented in Fig. 6. Fracture toughness decreases correlates with load peak values. Fixed value of the first delamination fragment $G_{I C}=153 \mathrm{~J} / \mathrm{m}^{2}$ was taken to describe delamination criteria in FE model.

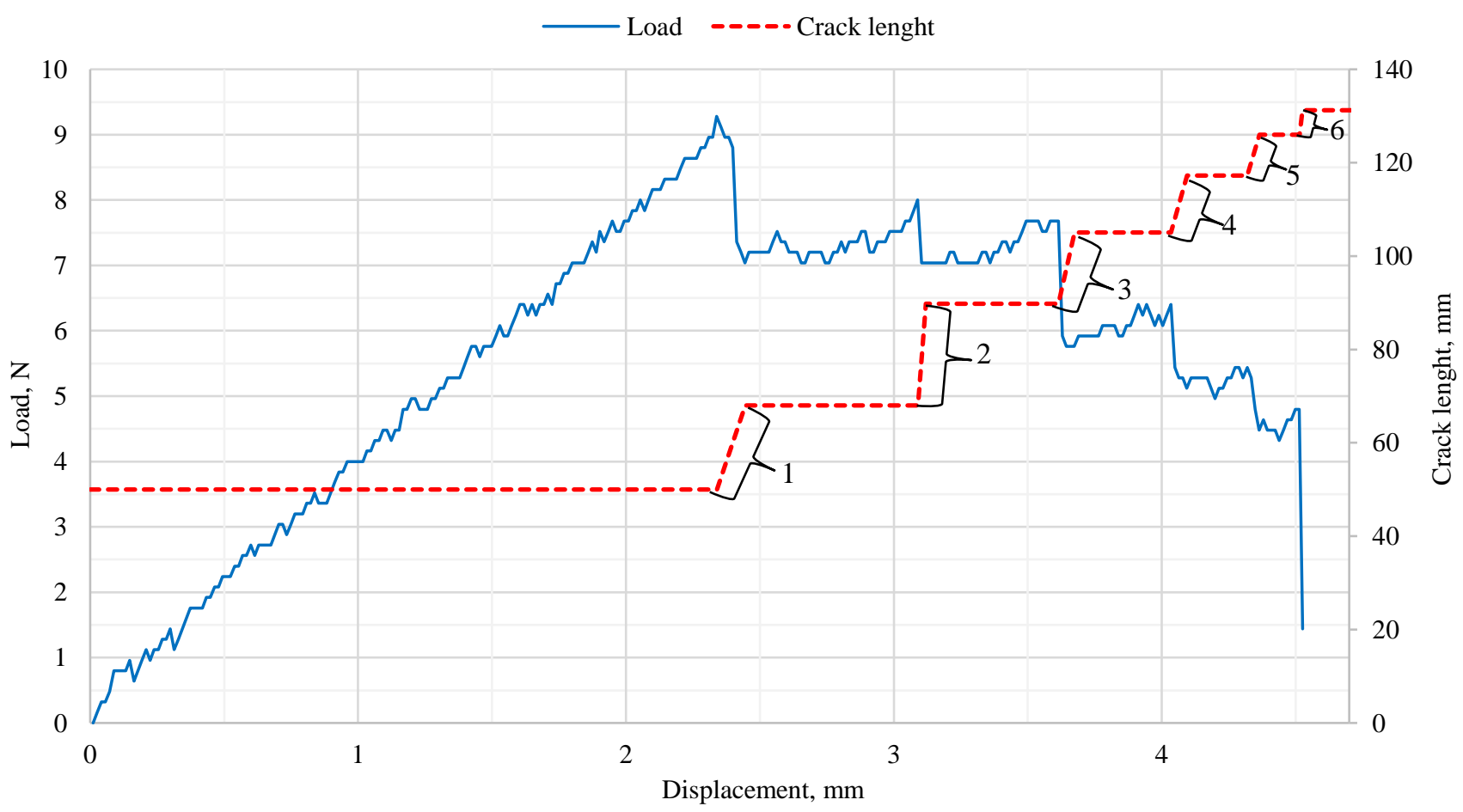

Fig. 4 Force vs. displacement and crack growth vs. displacement in combined graph 


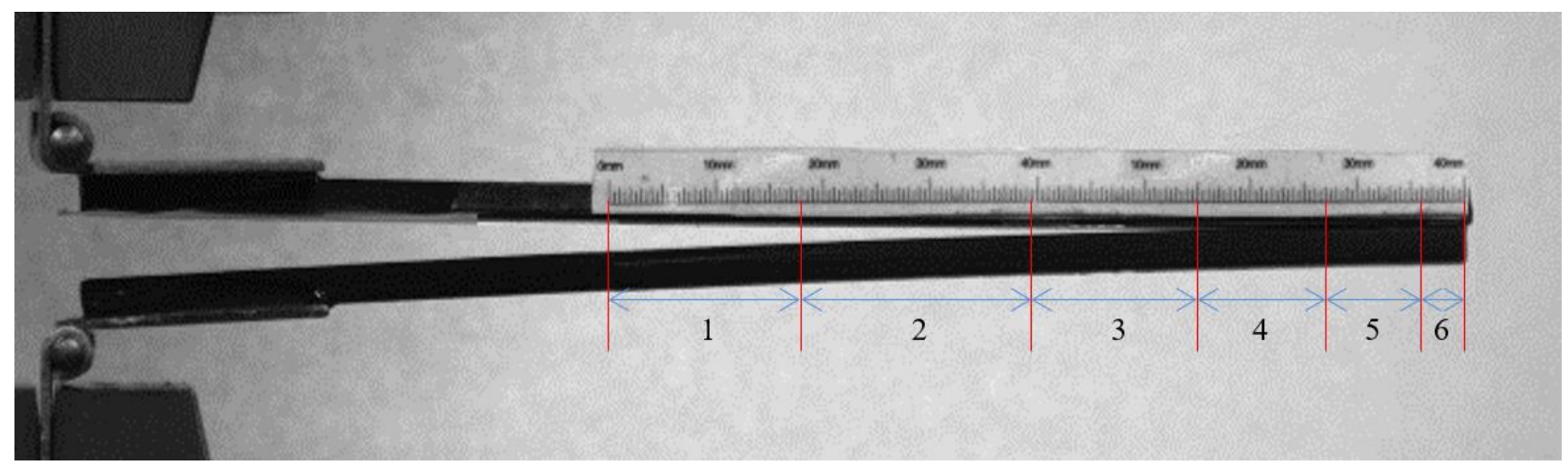

Fig. 5 Increments of unstable delamination growth during DCB test

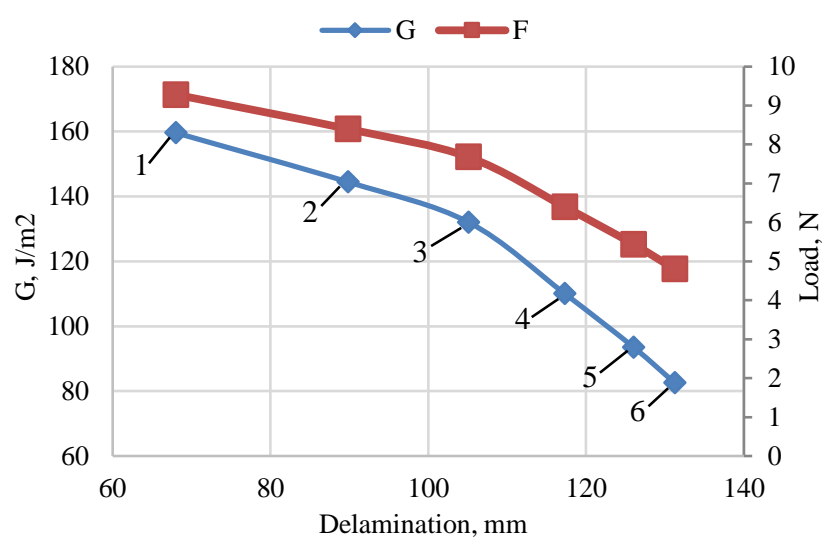

Fig. 6 Fracture toughness and load change

\subsection{Fracture toughness Mode II}

Fracture toughness for the mode II has been determined using three-point bending test where the specimens had initials pre-crack of the $50 \mathrm{~mm}$ length.

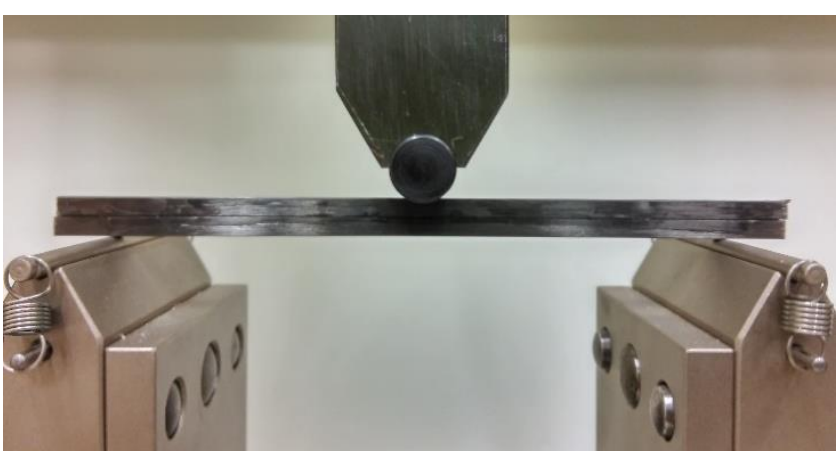

Fig. 7 Three-point bending test (Mode II)

Following crack propagation and following its length during mode II delamination is challenging, if there is no gap created in contrast to mode I where the fracture development is detected relatively easily.

Interlaminar fracture toughness for mode II was calculated [9]:

$$
G_{I C}=\frac{9 F^{2} \cdot a^{2} \cdot \delta_{I I}}{b\left(\frac{L^{3}}{2}+6 a^{3}\right)},
$$

here: $\delta_{I I}$ is load point displacement (mode II).
The average values of 10 experiments were $325 \mathrm{~J} / \mathrm{m}^{2}$. Zhi-peng Zhong and Hong Liu [10] obtained similar value of $365 \mathrm{~J} / \mathrm{m}^{2}$ for bonded composite material.

In FE model the initial value before the calibration of interlaminar fracture toughness at mode II assumed equal to $G_{I I C}=300 \frac{\mathrm{J}}{\mathrm{m}^{2}}$.

\section{Numerical simulation}

Delamination in LS-Dyna can be simulated using tiebreak contact or cohesive zone elements [11]. Both are based on fracture mechanics "Cohesive Zone Modeling" (CZM) approach.

Cohesive zone elements do not represent any physical material properties but describe the cohesive forces which occur when material elements are being pulled apart. The cohesive zone is a surface between sublaminates or plies where displacement discontinuities occur. This is appropriate methodology to predict the global failure at various scales of composite debonding such as decohesion between the matrix and fibres and delamination between the laminae by introducing the local fracture parameters [10].

Definition Tiebreak contact is based on the theoretical formulation of cohesive elements. The main advantage of this contact type is that there is no need to separately model cohesive elements between plies where delamination is expected. While both approaches are based on the same "Cohesive Zone Modeling" method, using tiebreak contact between sublaminates is a more effective method to simulate delamination in laminated composite structures [12].

Tiebreak contacts are active for nodes which are initially in contact. Failure strengths (normal and shear) and interlaminar fracture toughness must be for tiebreak contact if simulation of delamination process is expected. Under tensile load, tiebreak allows the separation of the surfaces and ultimately the failure of the tied surfaces will occur under the following failure criterion [12]:

$$
\left(\frac{\sigma_{n}}{N F L S}\right)^{2}+\left(\frac{\sigma_{s}}{S F L S}\right)^{2} \geq 1,
$$

where: NFLS is normal failure stress experimentally obtained characteristic of interlayer; SFLS is shear failure stress.

Post failure in TIEBREAK contacts allows the 
node to interact with the segment as in traditional compression only contacts. In the numerical simulation to obtain similar damage to the experimental results, the contact with moment transfer function has been selected (Option: -11). When the critical opening ( $\delta_{I}^{F}$ from Fig. 8) is reached, the contact will be lost and the sublaminates are converted into two separate surfaces with regular surface to surface contact between them to prevent penetrations. Then failure of segment is assumed, and the tensile spring is deactivated.

The situation where delamination develops under tensile and shear loading conditions are known as mixedmode. To evaluate the delamination in case of mixed mode loading the Benzeggagh-Kenane law has been chosen. Ultimate mixed-mode displacement [11]:

$$
\delta_{F}=\frac{2\left(G_{I C}+\left(G_{I I C}-G_{I C}\right)\left(\frac{\beta^{2} \cdot C T}{C N+\beta^{2} \cdot C T}\right)^{|P A R A M|}\right)}{\delta_{0}\left(\frac{1}{1+\beta^{2}} C N^{\gamma}+\frac{\beta^{2}}{1+\beta^{2}} C T^{\gamma}\right)^{1 / \gamma}},
$$

here: $\delta_{0}$ is load point displacement (mixed mode); $\gamma$ is Benzeggagh-Kenane law (default $=1.0$ ); $C N$ is the stiffness normal to the plane of the cohesive element; $C T$ is the stiffness in the plane of the cohesive elements; PARAM is exponent of the mixed mode criteria ( $P A R A M=-2.28)$.

"Mode mixity":

$$
\delta=\frac{\beta_{I I}}{\beta_{I}} .
$$

In the Fig. 8 presented schematic bilinear separation law model and explanation of parameters for Eqs. (7) and (8). In the graph "NFLS" refers to peak traction in normal direction and "SFLS" is peak traction in tangential direction.

To calibrate the interlaminar shear strength and fracture toughness three quasi-static experiments (threepoint bending test, mode I and mode II delamination) has been simulated using explicit finite element code LS-DYNA v.971 R7.1.2. Carbon fibre stripe was modelled by shell elements consisting of six laminas as orthotropic plane stress

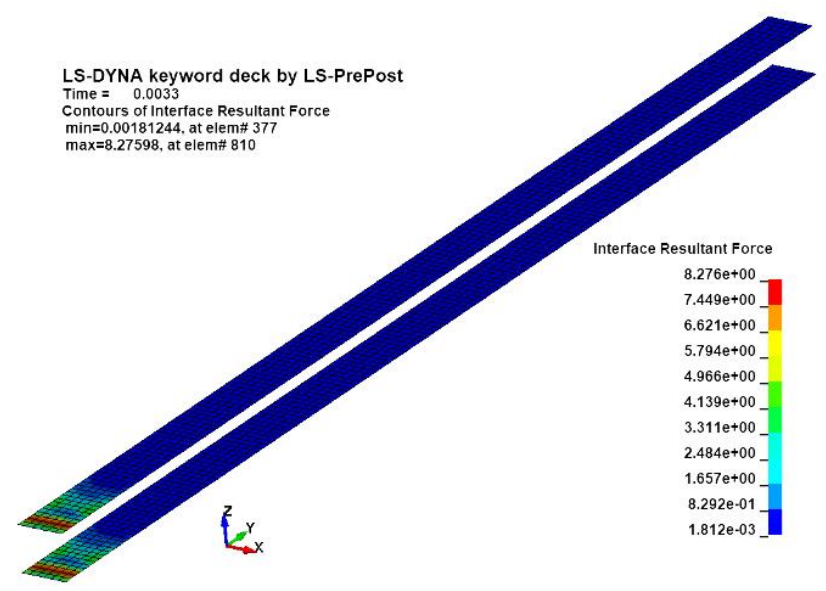

a homogenized continuum materials [13].

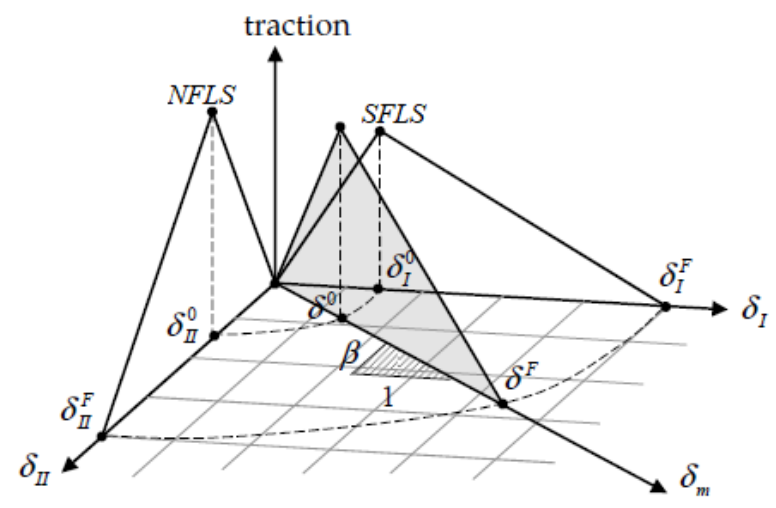

Fig. 8 Mixed-mode traction-separation law [11]

In present work tiebreak contact (*CONTACT_AUTOMATIC_ONE_WAY_SURFACE_T O_SURFACE_TIEBREAK) based on stress failure has been chosen to evaluate the delamination.

Mechanical properties of carbon fibre stripe experimentally obtained and used for FE simulation are presented in Table 1.

Table 1

Mechanical properties of carbon rods

\begin{tabular}{|l|l|}
\hline Longitudinal Young's modulus, GPa & 81 \\
\hline Transverse Young's modulus, GPa & 20 \\
\hline Major Poisson's ratio & 0.3 \\
\hline Shear modulus in the fiber direction, GPa & 15 \\
\hline Shear modulus transversely to the fiber, GPa & 15 \\
\hline Longitudinal compressive strength, MPa & 841 \\
\hline Longitudinal tensile strength, MPa & 1080 \\
\hline Transverse compressive strength, MPa & 841 \\
\hline Transverse tensile strength, MPa & 100 \\
\hline In-plane shear strength, MPa & 280 \\
\hline Tensile longitudinal failure strain & 0.02 \\
\hline Compressive longitudinal failure strain & -0.018 \\
\hline Tensile transverse (matrix) failure strain & 0.02 \\
\hline
\end{tabular}

First, validation of pure carbon fiber stripe under the 3-point bending test has been performed. The damage progression was simulated using material model MAT54 *MAT_ENHANCED_COMPOSITE_DAMAGE) based on Chang-Chang failure criteria [14] with Hashin's [15] four damage modes.

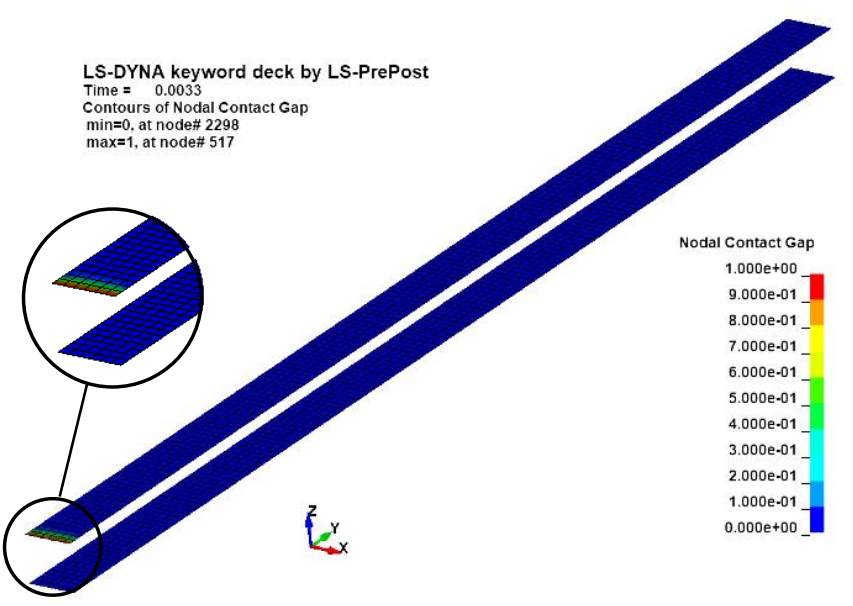
b

Fig. 9 Finite Element Analysis of delamination tests a) Mode I - Interface Resultant Force; b) Mode I - Nodal Contact Gap; c) Mode II - Interface Shear Stress; d) Mode II - Nodal Contact Gap 


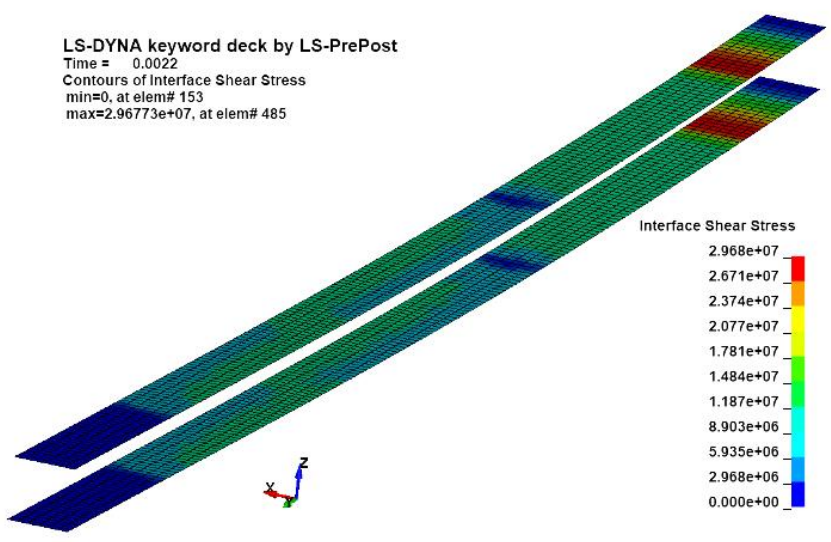

C

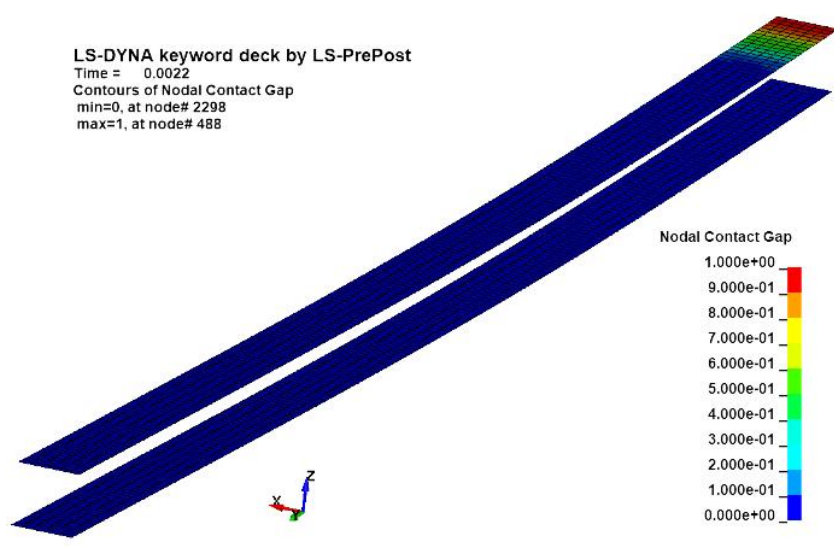

d

Fig. 9 Continuation

The visual distribution of interface resultant force, interface shear stresses and area of nodal contact gap at mode I (Fig. 9, a, b) and mode II (Fig. 9, c, d) are presented in Fig. 9. The stripes in Fig. 9 represents only the TIEBREAK contact areas. The growth of contact gap represents delamination area in experiments. The FE results of predicted delamination area matches experiments sufficiently.

\subsection{Parameters identification}

Adhesion and CF rod stiffness are very sensitive parameters for the delamination simulation. The wide range of scattering in experimental results and many of input parameters affect the reliability of simulation results and require the calibration of FE model.

A methodology for deriving material parameters from experimental results, known as parameter identification, is applied here using optimization procedure embedded in LS-OPT software. Parameter identification is non-linear inverse problems that can be solved using mathematical optimization, especially for the purpose of calibrating material models. The method involves minimizing the mismatch of two curves. Usually, these two curves consist of an experimental two-dimensional target curve and a computed curve. Depending on the material properties, the computed curve is a variable response. The optimization algorithm and the curve matching metric are the two key important components of an algorithm designed for parameters identification. To calculate the matching error, the original 'MeanSqErr' (MSE) function (9) in LS-OPT uses the vertical coordinate distance between two given curves. The mismatch is quantified in this function by the sum of the squares of the $y$ coordinate distances between the target points and the interpolated points on the computed curve. Thus, the abscissa mismatch is not explicitly included [15].

Difference between experimental and simulated data is evaluated by expression:

$$
M S E=\sum_{j=1}^{J} w_{j}\left(\frac{f_{j}-F_{j}}{s_{j}}\right)^{2},
$$

here: $F_{j}$ is target value; $f_{j}$ is simulation response; $w_{j}$ is weighting factor; $s_{j}$ is scale factor.

LS-OPT is capable to solve multi-objective optimization problems by defining several objectives in the Optimization dialog. In this case it was necessary to define more than one objective function for the model validation. Curve matching and maximum load value were the objectives with equal weighting factor. Optimization flowchart of metamodel-based parameters for delamination modelling is shown in Fig. 10.

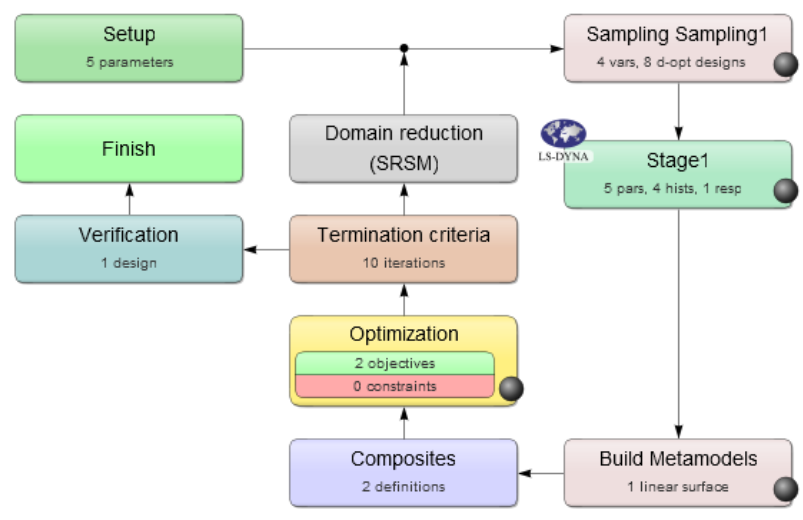

Fig. 10 Flowchart of optimisation model in LS-OPT GUI

In this study, parameters identification task was solved for mode I and mode II delamination experiments. Using calibrated material properties, the fracture toughness tests described in section 3.2 and 3.3 has been simulated with explicit FE models in LS-Dyna. Ranges of delamination parameters for optimization task presented in Table 2. Normal stiffness $(\mathrm{CN})$ in LS-OPT had constant value.

Table 2

LS-OPT parameters setup

\begin{tabular}{|c|c|c|c|c|}
\hline \multicolumn{2}{|c|}{} & min & $\max$ & calibrated \\
\hline \multicolumn{2}{|c|}{$\mathrm{CN}, \mathrm{TPa} / \mathrm{m}$} & \multicolumn{3}{|c|}{30} \\
\hline \multirow{2}{*}{ Mode I } & ERATEN, J/m ${ }^{2}$ & 100 & 200 & 155 \\
\cline { 2 - 5 } & NFLS, MPa & 40 & 80 & 57 \\
\hline \multirow{2}{*}{ Mode II } & ERATES, J/m ${ }^{2}$ & 300 & 600 & 375 \\
\cline { 2 - 5 } & $\mathrm{SFLS,} \mathrm{MPa}$ & 30 & 80 & 31 \\
\hline
\end{tabular}

The sensitivity of the results to each parameter mentioned in Table 2 is shown in Fig. 11, a) Mode I fracture toughness; b) Normal failure stress; c) Mode II fracture toughness; c) Shear failure stress). The calibrated values are 
marked in each picture on the color bar. For both delamination modes fracture toughness is more sensitive parameter

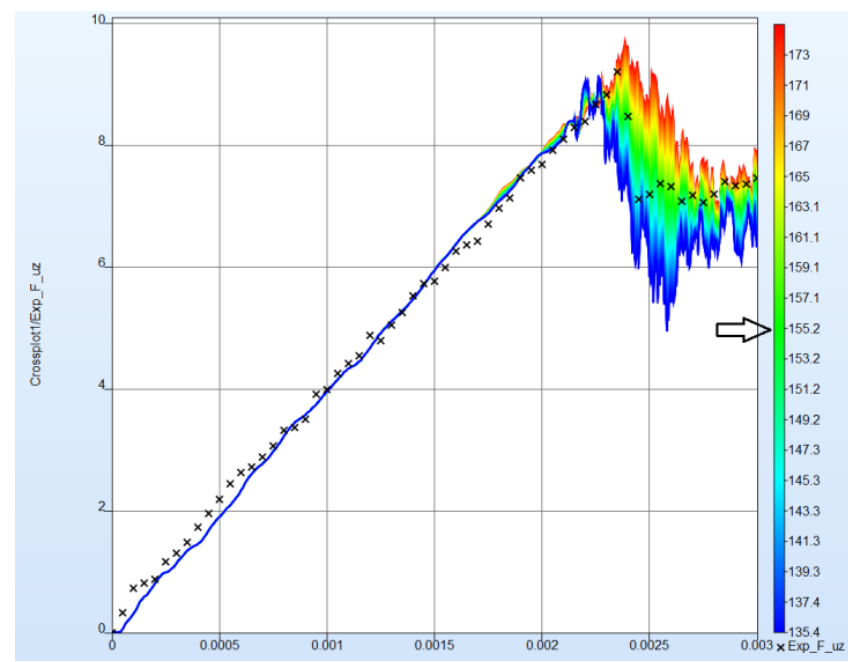

a

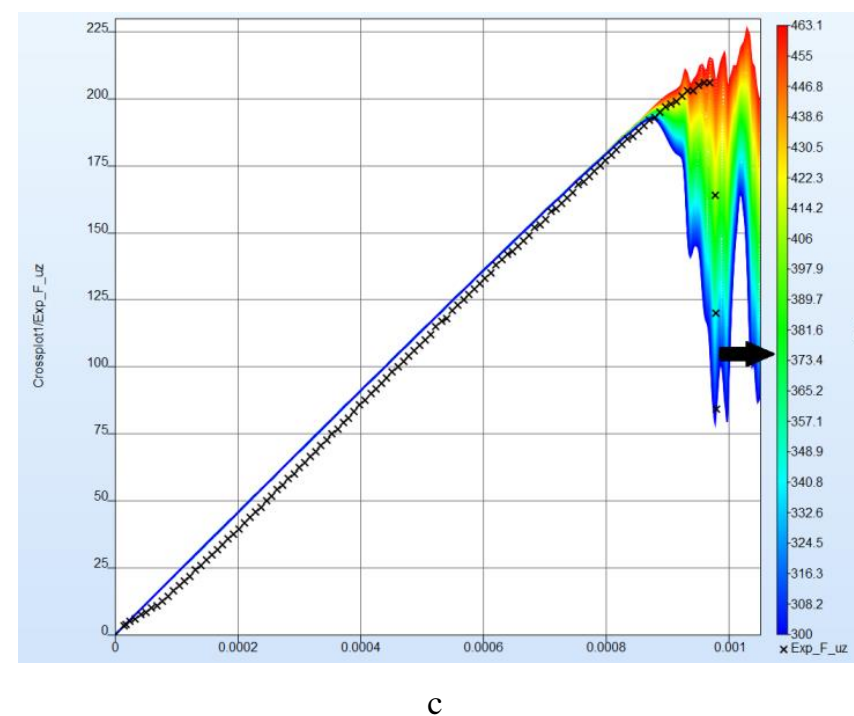

for the solution than failure stresses.

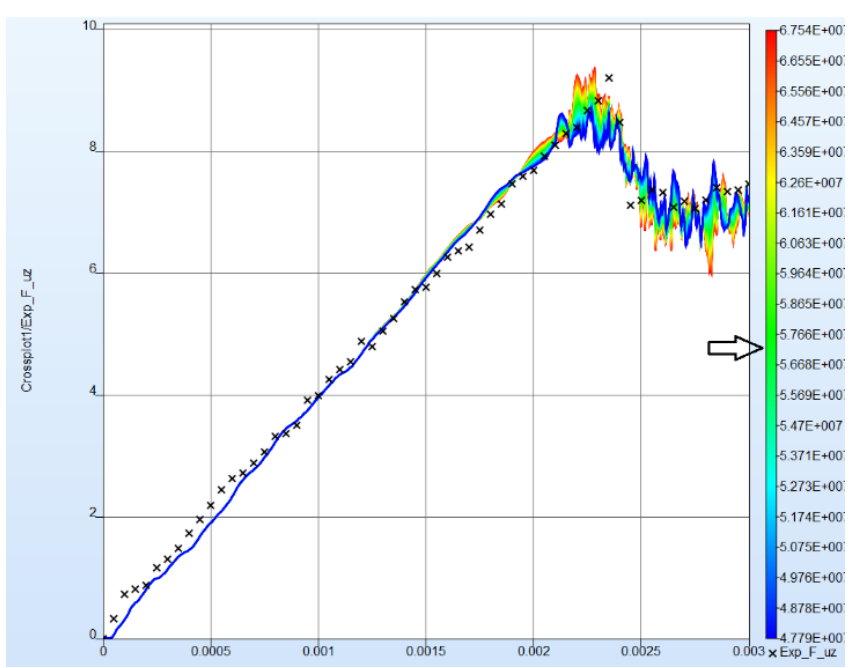

b

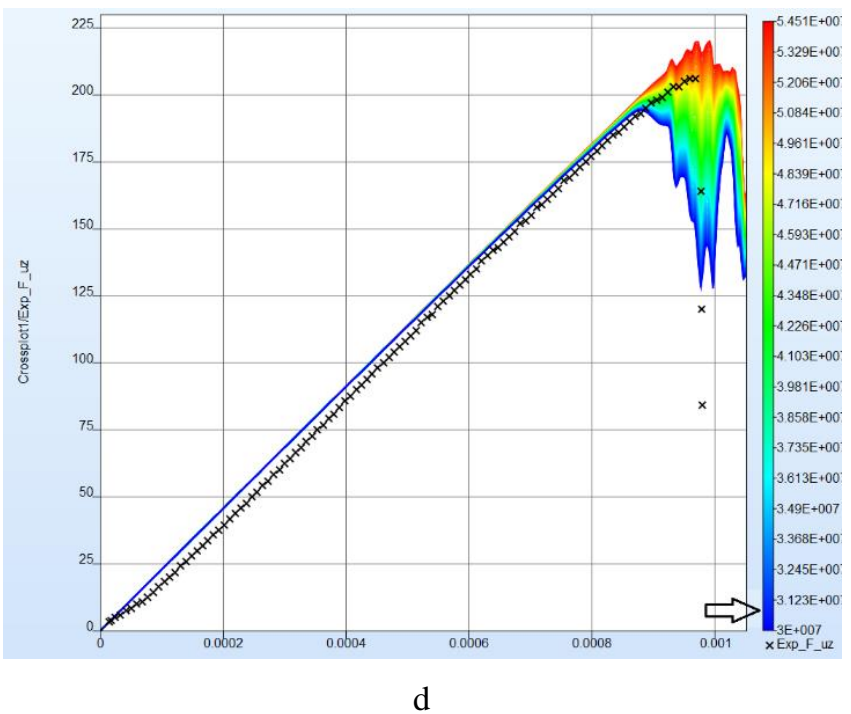

Fig. 11 Material model parameters sensitivities for mode I \& II simulation a) ERATEN (Mode I fracture toughness); b) NFLS (Mode I normal failure stress); c) ERATES (Mode II fracture toughness); d) SFLS (Mode II shear failure stress)

\section{Conclusions}

In this work the comparison of different experimental approaches to evaluate the interlaminar shear strength and fracture toughness of glued carbon fiber rods was performed. LS-OPT optimization tool based on curve fitting approach was used to calibrate the material model parameters for finite element simulation of delamination failure.

1. Interlaminar shear strength characteristics of glued carbon fiber rods have been compared using 5 different testing approaches. Average interlaminar shear strength varies from 4.5 MPa up to $32.5 \mathrm{MPa}$. Tensile test of double glued rods gave the smallest value of interlaminar shear strength. This method gives the most inaccurate values. Single shear test with average value of $6.2 \mathrm{MPa}$ also is quite far from the values obtained by other test methods. The smallest dispersion by three-point bending test.

2. Due to high stiffness of CF rods, unstable crack growth was observed during delamination (mode I) experiment. FE model of unstable Mode I delamination test was created using constant value of fracture toughness allows to sufficiently predict the delamination grow.

3. Calibration of material model parameters using LS-OPT tool shows that the interlaminar shear strength shall be determined by three-point bending test using short specimens (gap between supports $25 \mathrm{~mm}$ ).

4. Experimentally obtained force versus displacement curves from mode I and mode II delamination tests can be successfully adapted to identify interlaminar properties parameters such as interlaminar normal and shear strength, fracture toughness of modes I and II by using LS-OPT software.

\section{Acknowledgment}

This research is supported by Research Council of Lithuania (Project CompExSHM No.: P-MIP-19-523). 


\section{References}

1. Tomblin, J.; Seneviratne, W. 2011. Determining the Fatigue Life of Composite Aircraft Structures Using Life and Load-Enhancement Factors, Department of Aerospace Engineering National Institute for Aviation Research Wichita State University. http://www.tc.faa.gov/its/worldpac/techrpt/ar10-6.pdf.

2. Feraboli, P. J.; Kedward, K. T., 2004. In Search of the True Interlaminar Shear Strength, 19th, Joint American Society for Composites, American Society for Testing and Materials Committee D30.

https://www.lambolab.org/wp-content/uploads/03research/pub/04delam/2004-ASC-md_1.pdf.

3. Agastra, P.; Mandell, J. F. 2011. Testing and Simulation of Damage Growth at Fly Drops in Wind Turbine Blade Laminates, Department of Chemistry and Biological Engineering Montana State University. https://www.montana.edu/composites/documents/SAMPE\%202010\%20Agastra_Mandell.pdf.

4. Pagano, N. J.; Schoeppner, G. A. 2000. Delamination of polymer matrix composites: problems and assessment, Comprehensive Composite Materials 2: 433-528. https://doi.org/10.1016/B0-08-042993-9/00073-5.

5. Raišutis, R.; Kažys, R.; Žukauskas, E.; Mažeika, L. 2011. Ultrasonic air-coupled testing of square-shape CFRP composite rods by means of guided waves, NDT \& E International 44(7): 645-654.

http://dx.doi.org/10.1016/j.ndteint.2011.07.001.

6. Špakauskas, K.; Griškevičius, P.; Petkevičius, K.; Leišis, V. 2017. Testing and simulation of mechanical properties at bonded carbon fiber rods in glider wing spar, 22th International Conference "Mechanika 2017": 361-366.

7. Blake, S.; Berube, K.; Lopez-Anido, R. 2011. Interlaminar fracture toughness of woven E-glass fabric composites, Journal of Composite Materials: 1583-1592. https://doi.org/10.1177\%2F0021998311421221.

8. ASTM D5528 - Standard Test Method for Mode I Interlaminar Fracture Toughness of Unidirectional FiberReinforced Polymer Matrix Composites. https://www.astm.org/Standards/D5528.

9. ASTM D7905 - Standard Test Method for Determination of the Mode II Interlaminar Fracture Toughness of Unidirectional Fiber-Reinforced Polymer Matrix Composites.

https://www.astm.org/Standards/D7905.htm.

10. Zhi-peng Zhong, Hong Liu, 2017. Mode II fracture of GFRP laminates bonded interfaces under 4-ENF test, Advances in Materials Science and Engineering. https://doi.org/10.1155/2017/3792346.

11. LS-DYNA Keyword User's Manual Volume II Material Models. 2012.

12. Dogan, F.; Hadavinia, H.; Donchev, T.; Bhonge, P. S. 2012. Delamination of impacted composite structures by cohesive zone interface elements and tiebreak contact, Central European Journal of Engineering 2 (4): 612-626. https://doi.org/10.2478/s13531-012-0018-0.

13. Hallquist, J. O. 1998. LS-DYNA Theoretical Manual. Livermore Software Technology Corporation.

14. Chang, F. K.; Chang, K. Y. 1987. A progressive damage model for laminated composites containing stress concentration, Journal of Composite Materials 21 (8): 834-855. https://doi.org/10.1177\%2F002199838702100904.

15. Hashin, Z. 1980. Failure criteria for unidirectional fiber composites, Journal of Applied Mechanics 47 (2): 329334.

https://doi.org/10.1115/1.3153664.

\section{K. Špakauskas, P. Griškevičius, K. Petkevičius, V. Leišis \\ MATERIAL PARAMETERS IDENTIFICATION FOR MODELLING OF CARBON ROD STRUCTURES DELAMINATION}

S u m m a r y

The aim of the present work is to compare the interlaminar shear strength and fracture toughness of glued carbon fiber rods obtained using different experimental approaches and provide the effective way to characterise the interlaminar properties for reliable simulation of the delamination. Five different test methods (tension, single shear test, and double shear test, mode I and mode II delamination tests) were performed. Using the explicit LS-DYNA code the finite element model capable of simulating the damage process of bonded connection was developed. The interlaminar connection and delamination criteria were calibrated using the parameter identification methodology implemented in LS-OPT optimization tool.

Keywords: composites, delamination, parameters identification, mode I, mode II, LS-DYNA, LS-OPT.

Received May 10, 2017

Accepted December 07, 2021

This article is an Open Access article distributed under the terms and conditions of the Creative Commons Attribution 4.0 (CC BY 4.0) License (http://creativecommons.org/licenses/by/4.0/). 